\title{
RELAÇÃO DOS ESTADOS TRANSITÓRIOS DE HUMOR COM A PERFORMANCE EM COMPETIÇÂO DE FUTEBOL DE CAMPO DA CIDADE DE POUSO ALEGRE / MG
}

Gleivinilson dos Santos

\section{Resumo}

A pesquisa foi desenvolvida visando identificar as emoções apresentadas nos em atletas de futebol de campo durante competições.Realizaram-se testes para verificar qual o estado de humor predominante antes e após os jogos.O instrumento utilizado foi Poms, desenvolvido para permitir uma avaliação de perfis de humor.Os resultados mostram uma alteração significativa do resultado dos jogos no estado de humor geral pré e pós competitivo da equipe. Conclui-se que os que os estados negativos de humor obtiveram um aumento significativo no segundo jogo mesmo com a vitória e o estado tensão obteve uma variação pouco significativa com relação ao outros havendo uma maior mudança de no período précompetitivo, já o estado positivo vigor aumentou nas duas fase da competição.

\section{Palavras-Chave}

Futebol; Humor; POMS

\section{TRANSITÓRIOS OF THE RELATIONSHIP WITH THE PERFORMANCE OF HUMOR IN COMPETITION FOOTBALL FIELD OF THE CITY OF POUSO ALEGRE / MG}

Gleivinilson dos Santos

\begin{abstract}
The research was developed aiming to identify the emotions felt by Field soccer players during the competitions. Tests were applied to verify witch the predominant state of humor before and after the games. The instrument used was Poms method, developed to capable a valvation of humor profiles. The results show a significant alteration from games resulted in the general humor state of the team pre and post competitive. It was noticed that the negative state of humor got a significant increasing in the second game, even with is victory. There was a state of tension a little bit significant in relation with the other humor state having a bigger alteration in the period pre competitive. The positive state of vigor increased in its two phases from competition.
\end{abstract}

\section{Key-Words}

Futebol; Humor; POMS 


\section{INTRODUÇÃO}

O esporte hoje pode ser considerado como um dos maiores fenômenos sociais da modernidade (RUBIO et.al., 2000). E o futebol, como tal, é sem dúvida, parte principal deste fenômeno, pois se constitui de um espaço privilegiado para quem pratica, assiste e investe, tendo se transformado em um dos grandes responsáveis pelo aprimoramento físico e técnico em todo o mundo, além de toda a tecnologia que lhe é investida.

Tamanha é a sua importância que é, em longa escala, utilizado freqüentemente em iniciações esportivas, por ter e ser o elemento pedagógico importante na formação de crianças, bem como do papel desempenhado ao longo de sua tecnologia (RUBIO et.al., 2000).

Por se tratar de um esporte estimado, admirado e praticado no mundo inteiro, principalmente aqui no Brasil, disseminou-se de forma crescente a exigência da habilidade, do treinamento, da condição física e da excelência na performance, tornando-se estas valências, um motivo obrigatório em cada partida, ou seja, simplesmente um "show esportivo de habilidades" popularmente indispensável.

Adolfo Guilherme (1979) citado por Salomão (1987), diz que uma grande equipe não depende apenas da intensidade dos treinamentos e dos jogadores com suas habilidades, mas que deve ser encarada como fatores compostos de sentimentos e emoções.

Samulski (2002) citando Hackfort explica que as emoções presentes no esporte devem ser compreendidas como um sistema de relações psicofisiológicas e psicossociais.

Analisando este fato, sabe-se da tamanha importância que tem o técnico nessa relação, pois muitos atletas costumam se espelhar nele, aumentando ainda mais o compromisso e o dever deste para com a equipe e o time, sendo ele o total responsável para saber quando e como estimular os atletas.

O Perfil de Estados de Humor (Profile of Mood States - POMS), tem sido um dos instrumentos mais utilizados em psicologia para avaliar os estados emocionais e os estados de humor, assim como a variação que lhes está associada e foi construído para avaliar as variações dos estados de humor em população clínicas e não clínicas (FARO et al., 2001).

POMS é um questionário de auto-relato, de fácil e rápida utilização para captar os estados afetivos transitórios e flutuantes nos sujeitos, contribuindo decisivamente para a uma boa aceitação quer para 
investigação quer para intervenção. O contexto desportivo constituiu precisamente um dos domínios de utilização mais freqüentes do questionário (GOLOMAZOV, 1996). Este estudo corrobora na utilização do POMS em contexto desportivo centrando a monitoração dos estados de humor em atletas de alto-rendimento, revelando-se o instrumento como um precioso marcador ou avisador dos estados de humor dos atletas em jogo.

Desta forma, o presente estudo tem como objetivo verificar os estados transitórios de humor com a performance em uma equipe masculina de futebol do Guarani Esporte Clube de Pouso Alegre, da cidade de Pouso Alegre / MG.

Em complemento ao objetivo geral do estudo, serão também verificados:

- Índice de tensão durante a competição;

- Influência de emoções durante a competição;

- Maior ou menores sentimentos e variações desses sentimentos durante as competições;

- Sentimentos e variações de humores com o resultado dos jogos;

A importância que o esporte tem como fenômeno social é bastante nítida. Nos últimos anos, tem sido feito um grande esforço para entender e desenvolver o lado psicológico do futebol. Barros, Guerra (2004) dizem que este esforço se deve principalmente ao grande número de praticantes e no debate contínuo sobre a influência dos fatores emocionais no rendimento dos atletas.

Contudo este estudo visa determinar se a influência do acompanhamento psicológico do atleta pode alterar nas suas possibilidades máximas de rendimento, sendo sua característica a preparação psicológica em função do adversário, o desenvolvimento da auto-confiança e força de vontade, assim como a aplicação de medidas de motivação e orientação antes e depois da competição.

\section{OBJETIVO GERAL}

O presente estudo tem como objetivo principal verificar os estados transitórios de humor e sua relação com a performance, em uma equipe masculina de futebol do Guarani Esporte Clube, de Pouso Alegre, MG.

\section{METODOLOGIA}

\section{POPULAÇÃO DE ESTUDO}

Para a realização deste estudo serão selecionados 30 atletas de Futebol de Campo da equipe Guarani Futebol Clube de Pouso Alegre com idade aproximada de 16 a 24 anos 


\section{SELEÇÃO DA AMOSTRA}

Os 30 atletas que serão selecionados da equipe de Futebol da cidade de Pouso Alegre atenderão ao convite no qual será explanado inicialmente todos os procedimentos referentes ao questionário presente em Anexo, esclarecendo o estudo, todos receberão o Termo de Consentimento Livre e Esclarecido, o qual o participante oficializará sua participação.

\section{CRITÉRIOS DE INCLUSÃO E EXCLUSÃO}

Serão incluídos na pesquisa 30 atletas praticantes de Futebol de campo da equipe de Pouso Alegre entre 16 a 24 anos. Serão excluídos os atletas que não fazem parte da equipe de Pouso Alegre ou que não concordam participar deste estudo.

\section{INSTRUMENTOS}

Este estudo será submetido à análise do Comitê de Ética da Universidade do Vale do Sapucaí. Ao apresentarem-se como voluntários, os atletas e ou responsáveis participarão de uma reunião com a equipe de pesquisadores, no qual serão informados quanto aos objetivos e aos procedimentos metodológicos do estudo.

O consentimento para a participação no estudo por escrito será obtido de cada voluntário, após os esclarecimentos necessários, estando todos cientes de que a qualquer momento e sem constrangimento poderão deixar de participar do mesmo. Serão tomadas todas as precauções no intuito de preservar a privacidade dos voluntários. Para isto, todas as informações individuais obtidas durante o estudo serão sigilosas entre a equipe de pesquisadores e voluntários.

Segundo Faro (2001), o Perfil de estados de humor (Profile of Mood States - POMS) tem sido um dos instrumentos mais utilizados em psicologia para avaliar os estados emocionais e os estados de humor. Foi originalmente construído para avaliar as variações dos estados de humor em populações psiquiátricas, mas rapidamente a sua utilização foi direcionada para outras populações não clinicas. O contexto desportivo constituiu precisamente um dos domínios de utilização mais freqüente do questionário. Neste âmbito, o POMS tem sido usado para medir as variações emocionais associadas ao exercício e bem-estar psicológico a imposição de cargas de treino em atletas de modalidades anaeróbias e aeróbias, ou aos momentos pré e pós competitivos, a forma original de POMS foi validada e publicada por McNair e colaboradores (1971). Diversos estudos comprovam sua adequação para medir de forma sensível, precisa e válida os estados de humor dos indivíduos, quer em contexto psiquiátrico quer em população 
não psiquiátrica (BOYLE, 1987; MCNAIR et al.; 1971, NORCROSS, GUADAGNOLI; PROCHASKA, 1984; WECHOWIZC, 1978).

Deste conjunto de trabalhos emergiram fatores de estado de humor: tensão - ansiedade; depressão melancolia; hostilidade - ira; vigor - atividade; fadiga - inércia, e confusão - desorientação. Diversos estudos compravam a sua adequação para medir de forma sensível precisa e válida os estados de humor dos indivíduos, querem em contexto psiquiátrico quer em população não psiquiátrica (FARO et al, 2001).

\section{TRATAMENTO DOS DADOS}

Em seguida, os dados serão analisados avaliados através de correlações de Pearson e análises de variância com p-valor do teste $<0.05$.

\section{RESULTADOS}

No gráfico 01 - tensão: os valores significativos, acontece nos períodos pré competitivos houve um aumento da tensão antes do segundo jogo, se compararmos com o primeiro jogo que foi menor. Em se tratando antes do jogo, é um período de maior apreensão.

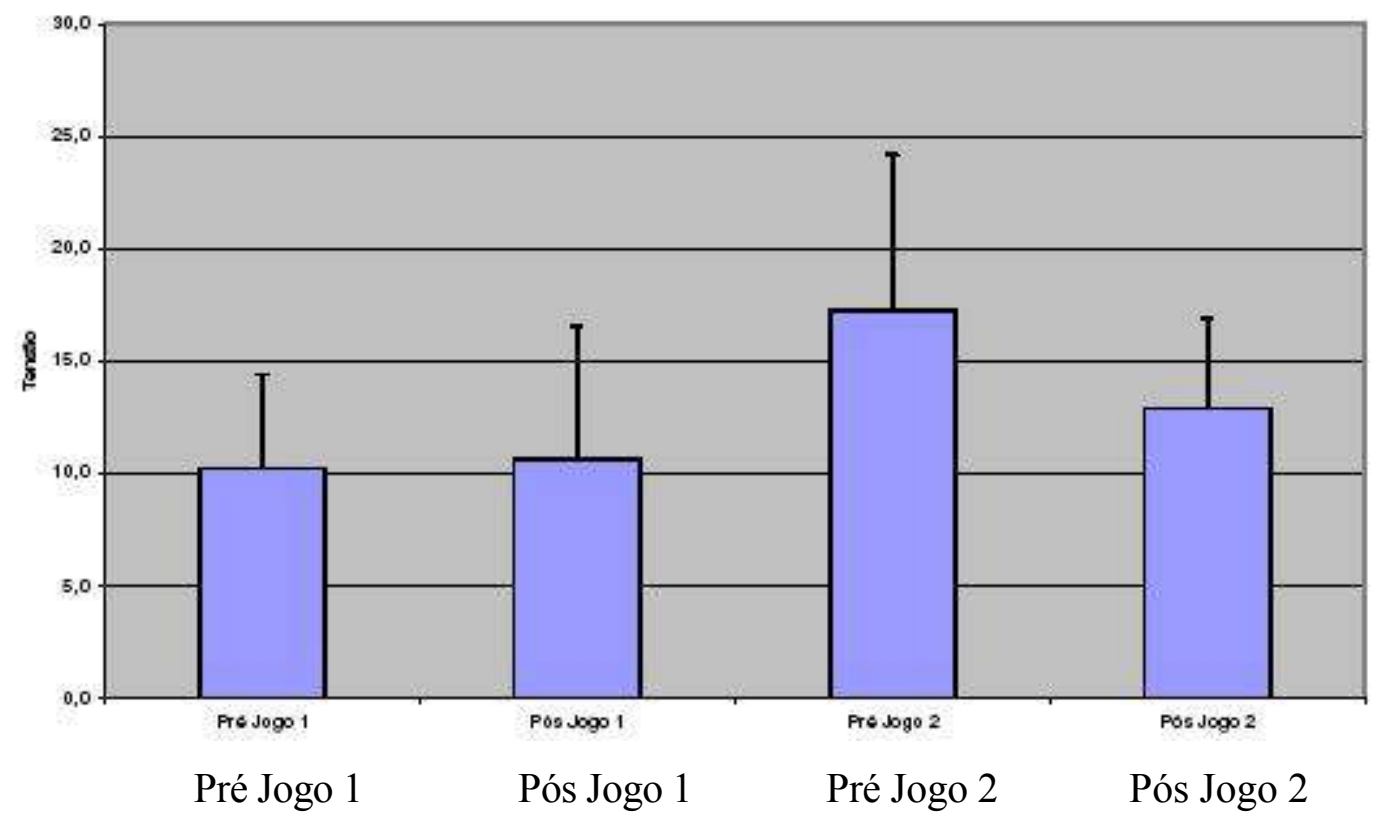

Figura 1- Referente à tensão 
No Gráfico 2 - depressão: houve uma grande oscilação, no período competitivo, sendo que no período pré-jogo do jogo dois foi maior considerando a relação aos outras situações de jogo, e no pós-jogo do jogo um este estado se manteve abaixo dos demais.

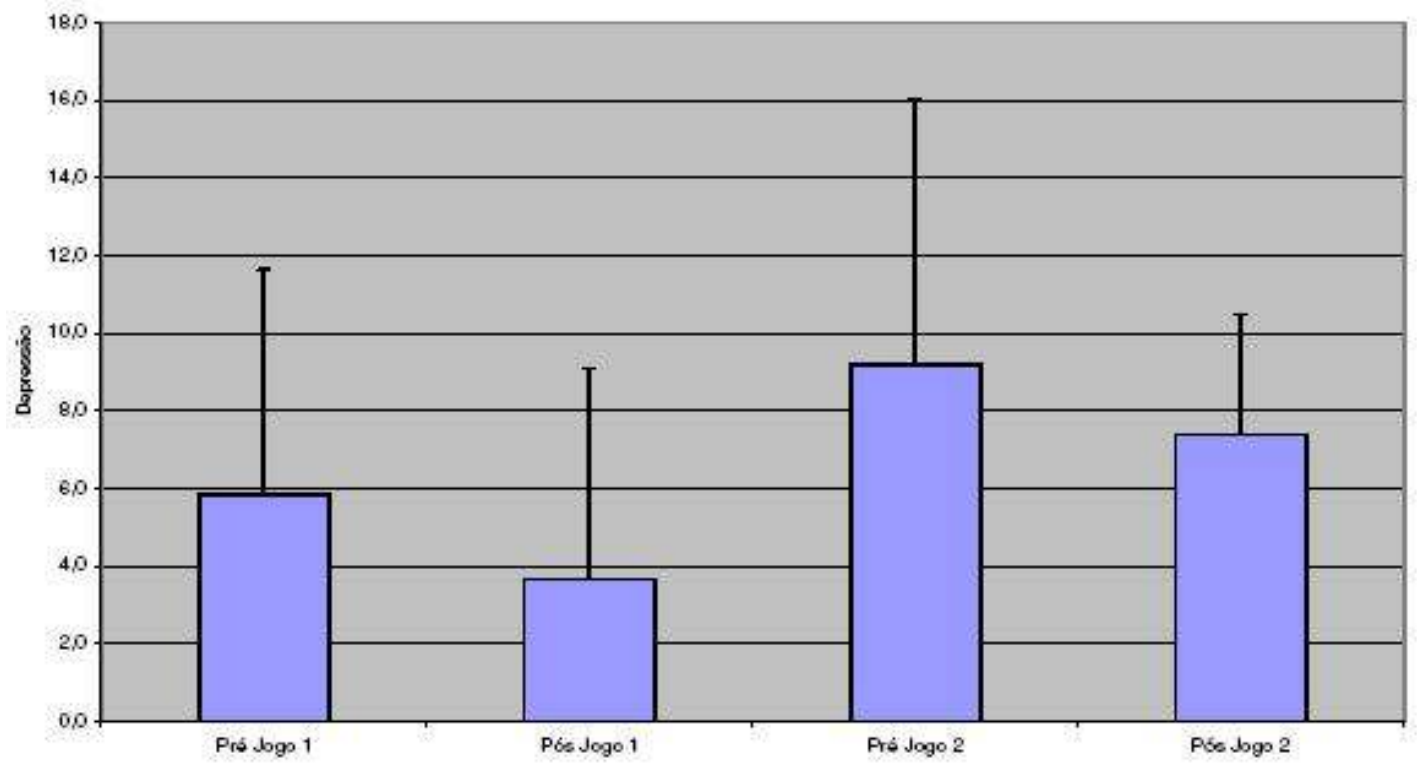

Figura 2: Referente à depressão

No Gráfico 03 - raiva: na situação pré-jogo do jogo dois, o fator raiva permaneceu elevadíssimo, se tratando de um estado de humor, importantíssimo na situação pré-jogo

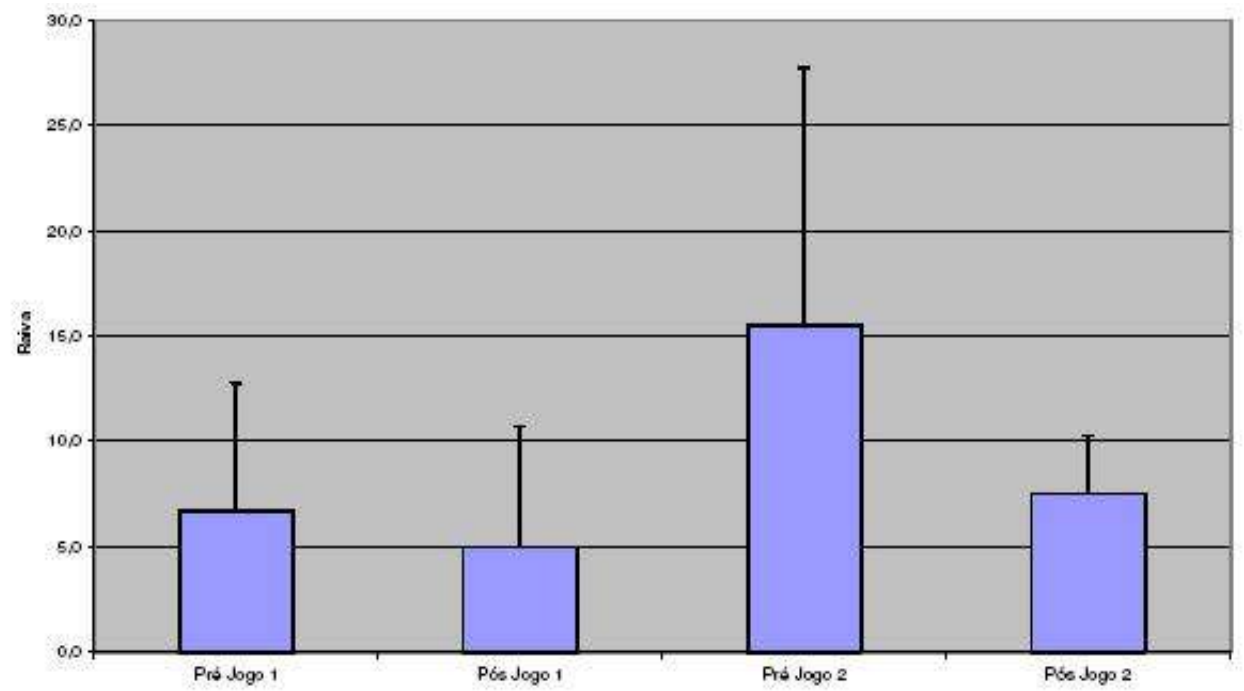

Figura 3 - Referente à raiva

No gráfico 04 - vigor: não houve nenhuma alteração considerável, apenas pequena oscilação. 


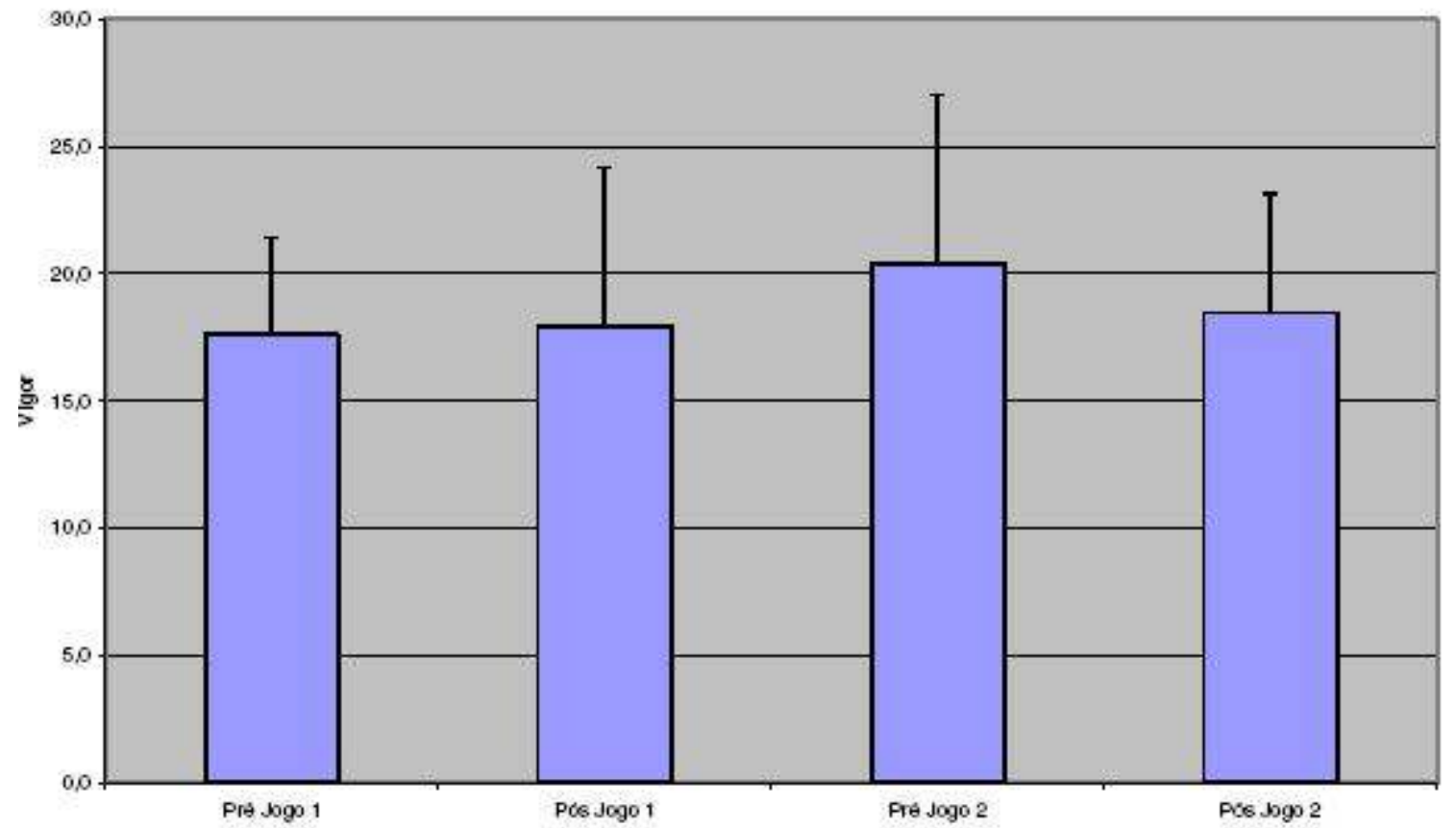

Figura 4 - Referente ao vigor

No Gráfico 05 - fadiga: está claro que as escalas pós-jogo do jogo um e a pós-jogo do jogo dois, ficaram elevadas, devido desgaste físico dos atletas, porem significativamente no pós jogo do jogo dois em relação aos momentos pré-jogo um e dois.

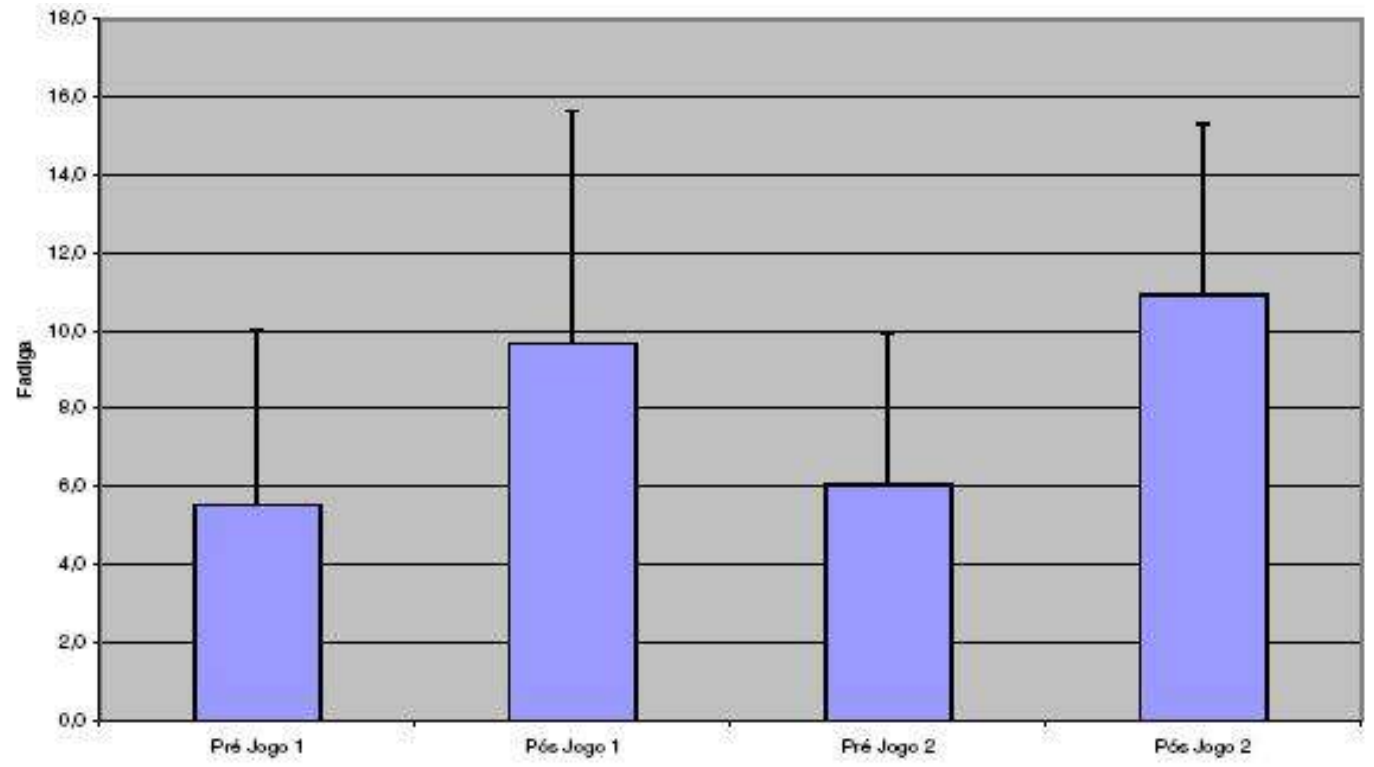

Figura 5 - Referente à fadiga 
No Gráfico 06 - confusão: houve um intensidade elevada em todos os pré, e pós jogos, mas foi maior no pré-jogo do jogo dois porém significante apenas em relação ao pós jogo do jogo um.

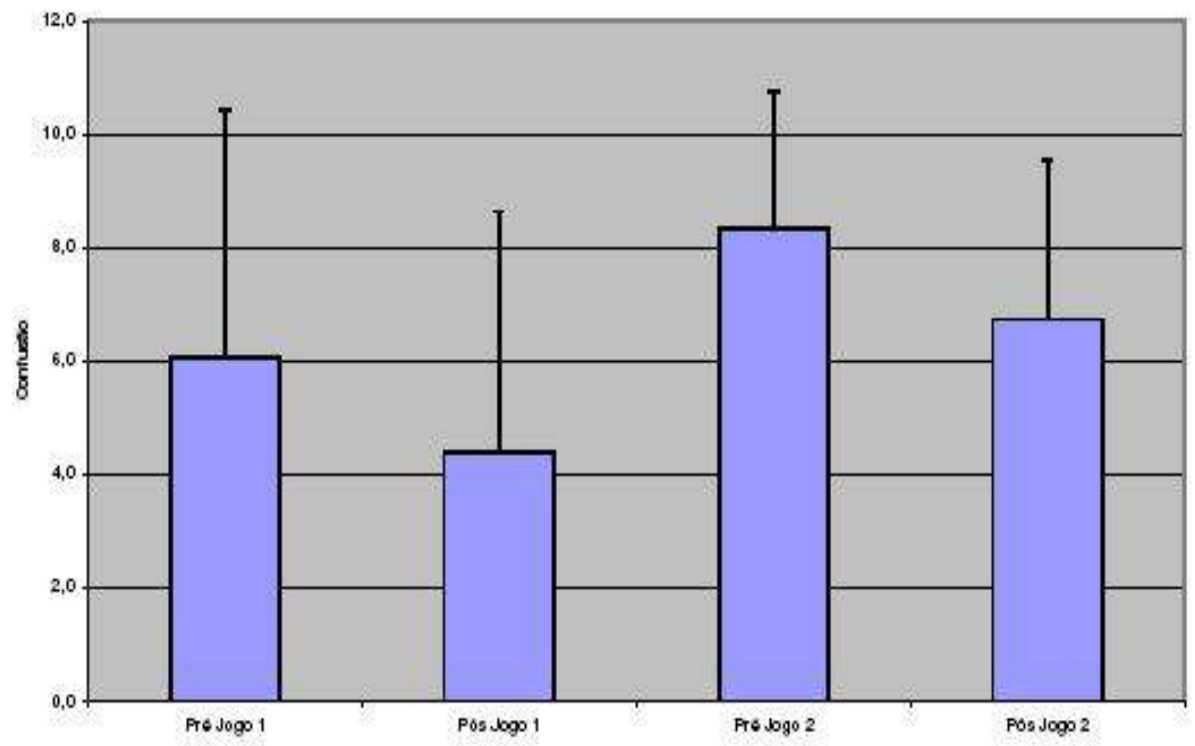

Figura 6 - Referente a confusão

\section{DISCUSSÃO E RESULTADOS}

Os dados do Teste POMS foram anotados em planilhas especificando cada avaliado, jogo e momento da competição, para serem analisados e calculados os estados de humor.

Em modalidades em que há competições com jogos diariamente, torna-se interessante e necessário verificar o perfil antes e pós-jogo, para que se possa adequar o estado de humor da equipe para o jogo subseqüente,d e forma que o estado psicológico do atleta não prejudique o seu desempenho (Silva, 2006). Após este procedimento, foram calculadas as médias e o desvio padrão de cada estado em cada um dos momentos de cada jogo. Em seguida, foi feita a análise de variância e pós-teste de comparação.

Os resultados que foram encontrados com este cálculo, demonstram um efeito significativo do resultado do jogo no estado de humor. Evidentemente, os atletas demonstraram maiores valores de aumento da tensão antes do segundo jogo em comparação ao primeiro jogo.

Porém, os resultados apontaram que todas as vezes que havia um melhor rendimento por parte dos atletas para os fatores estudados, ocorria uma pequena elevação da tensão, o que Rebustini (2005), relaciona à um estado de alerta do atleta, não podendo ser analisado como valor negativo ou prejudicial ao 
desempenho e ao comportamento do atleta, o que pode, talvez, justificar porque a tensão apresentou estes resultados.

Silva (2006), explica que, no decorrer de um campeonato, há uma grande variação nos estados de humor, onde estes estão relacionados ao estresse, o que explica um valor acentuado na tensão depois de uma possível perda do jogo.

Em se tratando do quesito depressão, houve uma grande oscilação, no período competitivo, sendo que no período pré-jogo do jogo dois, foi maior considerando a relação aos outras situações de jogo, e no pós-jogo do jogo um, este estado se manteve abaixo dos demais.

Para a analise do quesito raiva, na situação pré-jogo do jogo dois, este fator permaneceu elevadíssimo, principalmente por se tratar de um estado de humor importantíssimo na situação pré-jogo.

No estudo de Silva (2006), em contradição, o fator raiva não foi encontrada diferença significativa ente os valores pré-competitivos como os pós-competitivos, resultados estes que foram obtidos quando o time perdeu (resultados maiores ) e quando ganhou (resultados menores).

$\mathrm{Na}$ avaliação do vigor, não houve nenhuma alteração considerável, apenas pequena oscilação, mais presente no final dos jogos.

Para o fator vigor, Werneck et al. (2002) relatam que estes resultados sempre são esperados, em vista que a situação de possível derrota pode impor um estresse psíquico maior aos atletas e uma desmotivação que é refletida na diminuição deste quesito.

Nas situações de fadiga, está claro que as escalas pós-jogo do jogo um e a pós-jogo do jogo dois, ficaram elevadas, devido desgaste físico dos atletas, porém mais significativamente no pós-jogo do jogo dois, em relação aos momentos pré-jogo um e dois.

Já Werneck et al. (2002), quando cita Hassmén e Blomstrand (1995), esclarece em sua pesquisa, que quando o time perde, esse resultado é maior, mas os outros autores destacam que o fator pós-competitivo é maior, independentemente do resultado final do jogo, porém indicando sempre haver um aumento deste. 
Por fim, na avaliação do quesito confusão, houve um intensidade elevada em todos os pré e pós jogos, mas foi maior no pré-jogo do jogo dois, porém significante apenas em relação ao pós jogo do jogo um., conforme também relata Silva (2006) quando cita Werneck et al. (2002).

Assim, destaca-se que o período pré-competitivo é um tempo de maior concentração, reflexão, autoavaliação, comparação e pré-julgamento com relação a todas as possíveis situações que a equipe enfrenta no jogo. E é nesse período que surgem as inseguranças, os receios, as convicções e as certezas, predominando o estado de ansiedade (SILVA, 2006).

Em relação a isto, Samulski (2002), relata que minutos antes da competição, o atleta costuma se encontrar num estado de intensa carga psíquica, o que se caracteriza pela antecipação dos riscos e conseqüências possíveis, podendo isso haver alterações no seu rendimento durante a competição.

Dessa forma, ressalta-se mais ainda que o perfil dos estados de humor - POMS - tem sido um dos instrumentos mais utilizados para avaliar os estados emocionais e de humor dos atletas em relação à performance. Perfil este destacado nesta pesquisa, e comprovado que para qualquer competição que se tenha, sempre ocorrerá mudanças nos estados transitórios de humor pré e pós-competitivo, independentemente se houver perca ou vitória do time na competição que disputam.

E que estes valores estariam relacionados ao sucesso esportivo e a alta performance, sendo efetivo para prever o desempenho esportivo.

\section{CONCLUSÃO}

Com este estudo, pode-se concluir que os estados negativos de humor aumentam quando a equipe perde. Visto que os resultados obtidos mostram uma alteração dos estados de maneira significativa, principalmente em relação ao resultado dos jogos nos estados de humor pré e pós competitivo da equipe. Mesmo a equipe vencendo as duas partidas, os atletas apresentaram números avançados nos estados vigor, confusão e fadiga e menores valores para tensão,depressão, raiva.

Silva (2006) destaca, portanto, que o "controle das emoções negativas é essencial para o sucesso competitivo ", e que "manter-se calmo, relaxado e concentrado são características relacionadas diretamente com a habilidade de manter a energia positiva em valores máximos". 
Assim, os fatores psicológicos, como os estados de humor, interferem na performance esportiva, devendo ser considerados na preparação do atleta, visando um equilíbrio psicofisiológico, que influenciará diretamente no seu desempenho.

Portanto, o mais indicado em qualquer situação, é a intervenção psicológica para a regulação desses estados, melhorando o preparo a fim de minimizar o desgaste psicológico da competição e maximizar a performance dos atletas de qualquer modalidade, mas especificamente o futebol de campo, nossa paixão nacional.

\section{REFERÊNCIAS}

BARROS, T.; GUERRA, I. Ciência do futebol. São Paulo: Manole, 2004.

DUARTE, N. Formação do indivíduo, consciência e alienação: o ser humano na psicologia de A. $N$. Leontiev. Cadernos CEDES, Campinas, v. 24, n. 62, p. 44-63, abr. 2004. Disponível em: $<$ www.boletimef.org $>$

FARO, M. V.; ALMEIDA, P. L.; SANTOS R. C. Adaptação portuguesa da versão reduzida do Perfil de Estado de Humor - POMS. Análise Psicológica, 2001 - Scielo. oces. mctes. Pt

GOLOMAZOV S, SHIRVA B. Futebol: treino da qualidade do movimento para atletas jovens. São Paulo: FMU, 1996.

MACHADO, A. A. et al. Psicologia do esporte: temas emergente I. São Paulo: Ápice, 1997.

MIRANDA, A. de L. A. Uma interpretação da aquisição de conhecimento do psicólogo esportivo.

2003. 48f. Monografia (Pós-Graduação em Psicologia Aplicada ao Esporte de Alto Rendimento) Universidade Veiga de Almeida, Rio de Janeiro. 2003. Disponível em: <www.boletimef.org>.

PELUSO, M. A . M. Alterações de humor associadas à atividade fisica intensa. São Paulo, 2003

REBUSTINI, F. Estados de humor e percepção de bem estar: um estudo com jovens mulheres voleibolistas. Revista Digital, Buenos Aires, a. 10, n. 86, 2005. Disponível em: < www. efdeportes.com.> RUBIO, K., et al. Psicologia do esporte: interfaces, pesquisa e intervenção. São Paulo: Casa do Psicólogo, 2000.

SALOMÃO, L. C. Esportes: afeto ou agressão?: uma visão revolucionária do mundo dos esportes. São Paulo: Próton, 1987.

SAMULSKI, D. M. Psicologia do esporte. São Paulo: Manole, 2002.

SANTOS FILHO, J. L. A. dos. Manual de futebol. São Paulo: Phorte, 2002. 
SILVA, A. C. da. Relação dos estados transitórios de humor e a performance em competição de handebol. Universidade do Vale do Sapucaí, Pouso Alegre, 2006.

SOUZA FILHO, P. G. O que é a psicologia dos esportes. Rev. Bras. Ciên. e Mov. v. 8, n. 4, p. 33-36, 2000. Disponível em: <www.boletimef.org $>$

VALLE, M. P. do. Atletas de alto rendimento: identidades em construção. 2003. 97f. Dissertação (Mestrado em Psicologia Social e da Personalidade) - Faculdade de Psicologia, Pontifícia Universidade Católica do Rio Grande do Sul, Porto Alegre, 2003. Disponível em: < www.boletimef.org> WERNECK, F. Z.; COELHO, E. F.; Ribeiro, L. C. S. Relação dos estados de humor e a performance em voleibolistas. Coletânea de textos em estudos olímpicos. Rio de Janeiro: Gama Filho, 2002. 


\section{Gleivinilson dos Santos}

Universidade do Vale do Sapucaí - UNIVÁS - 2007

\section{Referência do artigo:}

\section{ABNT}

SANTOS, G. Relação dos estados transitórios de humor com a performance em competição de futebol de campo da cidade de Pouso Alegre / MG. Conexões, v. 6, p. 596-608, 2008.

\section{APA}

Santos, G. (2008) Relação dos estados transitórios de humor com a performance em competição de futebol de campo da cidade de Pouso Alegre / MG. Conexões, 6, 596-608.

\section{VANCOUVER}

Santos G. Relação dos estados transitórios de humor com a performance em competição de futebol de campo da cidade de Pouso Alegre / MG. Conexões, 2008; 6: 596-608. 